\title{
1. Building shared knowledge capital to support natural resource governance in the northern periphery: concepts and challenges
}

\author{
John McDonagh, Seija Tuulentie and Ari \\ Nikula
}

\section{INTRODUCTION}

Peripheral livelihoods and land use depend heavily on natural resources. Most northern and Arctic communities, characterized by low population densities and vulnerability to extreme weather, climate change and habitat fragmentation, are also challenged by pressures of food and energy security and environmental protection. Consequently, there is growing interest in supporting holistic decision-making processes concerning how natural resources are used, how landscapes are managed and ultimately how peripheral rural regions, with their often unique traditions, culture and land use practices, are managed and protected for future generations. The challenge for contemporary decision-making processes therefore is one of reconciling diverse land use modes which acknowledge, combine, and make use of local knowledge side by side with scientific and other expert knowledge. It is important to recognize also that decisions made about how resources are used, by whom and to what extent, affect not only the resource itself but also the communities in which the resources are found. Thus, it is the premise of this book that all stakeholders, many of whom have diverse or conflicting priorities, need to be involved in developing an integrated and shared knowledge base from which decision-making on natural resources and their dependent communities can be made. If such a circumstance is allowed to develop it will inform not only processes for collaborative engagement, but will stimulate better governance of land use and natural resource management and planning. Such a movement will enhance local authorities' and local stakeholders' abilities to collect and transfer knowledge among those who represent the compendium of economic, 
cultural and social backgrounds that exist in these areas. The desired goal then, is one of creating a scaffold for greater community derived decision-making processes around environmental management that enhances not only the development of communities but also maintains balanced views of environment, economic and social interests that in turn enhance the likelihood of long-term sustainability.

\section{PAYING THE PRICE - COMPETING KNOWLEDGE SYSTEMS AND NATURAL RESOURCES}

In our contemporary world, the challenges of climate change, food and energy security are nowhere more clearly played out than in peripheral rural areas. These challenges that peripheral areas face are not unique to them, and do not merely concern their inhabitants, but they are very often locales in which key environmental struggles with far-reaching implications will be won and lost. What is most interesting about these arenas, where conflict, dispute and compromise are commonplace, is that very often there is a tendency to impose 'solutions' from above with little regard to what society and the everyday experience can contribute from below. Consequently, the reliance on a 'science knows best' trajectory has been permeated throughout history with contestation and feelings of powerlessness (see Tovey, 2009). Indeed, Nakashima (2010) questions why science retains such dominant and powerful influence, arguing that science is but 'one knowledge system among many (while) other knowledge systems, many of them embedded in a remarkable diversity of cultures ... constitute a rich and diverse intellectual heritage whose importance for attaining international development objectives ... continues to be underestimated' (p. 1). This local or indigenous knowledge, an intangible but globally relevant concept, has thus grown in legitimacy and has begun to be seen as an important source of learning and understanding. So, rather than actions, being taken by policy makers or government bodies, drawing solely from science to address problems in peripheral rural regions, cognizance must be taken of local needs and the valuable insights that can be garnered from local and indigenous knowledge; knowledge that Nakashima (2010) describes as comprising 'the understandings, skills and philosophies that span the interface between ecological and social systems, and intertwine nature and culture' (p. 1).

This book then explores this much under-researched area in the context of environmental management and natural resource governance. In particular, what makes this book stand apart is its focus on northern peripheral rural regions where there is growing concern regarding increased global interest in Arctic natural resources and the use / misuse of these resources and the implications this has both for the communities in which these resources are 
located and, more broadly, for environmental sustainability. The goal of the book is one of highlighting the importance of integrating local and indigenous knowledge into the decision-making process around land use management. In doing this, it is our contention that we will encourage more thoughtful co-operation between stakeholders and, ultimately, enable greater potential for sustainability-driven decision-making. This co-production of knowledge methodology is subsequently advanced with a view to creating a facilitating framework which could be operationalized across sparsely populated areas. Such a framework, it is envisaged, would allow for the integration of ideals, processes and practices in a coherent and more cohesive way.

In advancing this methodology, this book, with its international perspective and contributions from the social and natural sciences, presents comprehensive and practice-relevant case studies from different northern rural contexts and landscapes. Further, the book presents novel techniques and tools, and highlights key issues and possible synergies across a range of landscapes in terms of their management. Indeed the main aim of the book is one of exploring the various methods and practices which have been used, or could be developed together with stakeholders, that improve the collection and utilization of locally relevant knowledge in decision-making and land use planning. In going about this task the various authors investigate ways in which local knowledge can be meaningfully integrated into decision-making processes, while also considering the ways in which indigenous and local knowledge (ILK) can be made more spatially explicit. In addition, the capacity of local communities and landowners to influence planning and resource management is probed in efforts to ascertain the ways in which public policy and civil society interests can be integrated into natural resource governance. A very interesting avenue that the book considers is the way in which tools such as participatory mapping based on GIS (PPGIS/PGIS) are used in sparsely populated rural areas and how such tools can enhance participation and give assistance to decision-makers concerning land use planning and natural resource governance. Other aspects of the book draw from broader debates around participatory governance systems and where, if at all, participatory and local knowledge becomes part of the process. The concept of Social Licence to Operate (SLO) is also critiqued from the nuances of self-regulation within different industries to the reach of such industries beyond legislation, towards voluntary participatory processes and social projects.

In all, the book outlines ways in which special emphasis can be placed on safeguarding the prerequisites for practising indigenous and local cultures when decisions are made concerning the use of land and natural resources in wilderness areas in accordance with Article 8(j) of the UN Convention of Biological Diversity. In doing this some very interesting concepts continually emerge, namely those of what constitutes 'local', 'traditional' and 'indige- 
nous' knowledge and how best they can be incorporated into contemporary decision-making practices. It is to these concepts we turn next.

\section{WHAT CONSTITUTES TRADITIONAL, INDIGENOUS AND LOCAL KNOWLEDGE?}

At a time when we see a dramatic shift in the way in which information is shared - being more widely available, often standardized and instant - we are also seeing a realization of the need for diversity in our ways of thinking about, and addressing, current and potential environmental problems. Regarded as objective, but in many ways reductionist and analytical, scientific knowledge is challenged in multiple ways by demands for more holistic, subjective and in many ways abstract knowledge (often termed traditional, local or indigenous knowledge) and the role it can play in creating alternative pathways for a sustainable future. The value of traditional knowledge was first acknowledged internationally in the UN Convention on Biological Diversity (CBD, 1992). Article $8(\mathrm{j})$ of the Convention obliges State parties to

respect, preserve and maintain the knowledge, innovations and practices of indigenous and local communities that embody traditional lifestyles relevant to the conservation and sustainable use of biological diversity and promote their wider application with the approval and involvement of the holders of such knowledge, innovations and practices and encourage the equitable sharing of the benefits arising from the utilization of such knowledge, innovations and practices.

Traditional knowledge is defined by CBD (2018) as referring to

the knowledge, innovations and practices of indigenous and local communities around the world. Developed from experience gained over the centuries and adapted to the local culture and environment, traditional knowledge is transmitted orally from generation to generation (and can take) the form of stories, songs, folklore, proverbs, cultural values, beliefs, rituals, community laws, local language, and agricultural practices, including the development of plant species and animal breeds. (p. 3)

A further attribute is Traditional Ecological Knowledge (TEK). TEK is defined by Berkes (1993, p. 2) as

a cumulative body of knowledge and beliefs, handed down through generations by cultural transmission, about the relationship of living beings (including humans) with one another and with their environment. It is knowledge held by indigenous peoples or local communities, encompassing language, naming and classification systems, resource use practices, rituals, spirituality and worldview. 
Critics of Berkes' definition argue TEK is much more than a 'body of knowledge' with McGregor (2004, p. 75) emphasizing that 'body of knowledge' gives an impression of knowledge that is separate from the people who hold and practise it; a position, she suggests, that does not acknowledge that culture, traditional livelihoods and knowledge holders are all tied together. It has also been pointed out that Berkes' definition conceptualizes TEK as a set of procedural ecological knowledges; for example, the knowledge of animal behaviour or plant distributions (Casimirri, 2003). According to Casimirri (2003) this definition somewhat ignores that TEK is dynamic and complex and connects biophysical and social processes. Indeed many researchers avoid using the concept 'traditional' because the term is seen to refer to static, historical knowledge, contrary to change. For example, Sami scholar Kuokkanen (2000) has written how "talking about "traditional" ways of life or "traditional" culture can suggest racist notions of a frozen culture giving rise to false views of authenticity and "traditional practices"' (p. 413). This, for its part, denies development and change in indigenous cultures. Therefore, the term Indigenous Knowledge (IK) is often used as a synonym of Traditional Knowledge, and the term Indigenous Ecological Knowledge (IEK) instead of Traditional Ecological Knowledge.

International bodies such as UNESCO use the term Indigenous and Local Knowledge (ILK). ILK is defined as 'the understandings, skills and philosophies developed by societies with long histories of interaction with their natural surroundings. For rural and indigenous peoples, local knowledge informs decision-making about fundamental aspects of day-to-day life' (UNESCO, n.d.). Local knowledge (LK) is seen as an umbrella term, which includes ILK and is defined as 'the knowledge that people in a given community have developed over time, and continue to develop' based on experience, adapted to local culture and environment and embedded in community practices, and not:

confined to tribal groups or to the original inhabitants of an area. Rather, all communities possess local knowledge - rural and urban, settled and nomadic, original inhabitants and migrants. There are other terms, such as traditional knowledge or indigenous knowledge, which are closely related, partly overlapping, or even synonymous with local knowledge. The term local knowledge itself however seems least biased in terms of its contents and origin as it embraces a larger body of knowledge systems, including those classified as traditional and indigenous. (FAO, n.d. p. 1)

In UNESCO reports, IK is defined as local knowledge which belongs to a specific ethnic group, being

knowledge that is unique to a given culture or society. It is the basis for local-level decision-making in agriculture, health care, food preparation, education, natural resource management, and a host of other activities in rural communities. 
(It) is the information base for a society, which facilitates communication and decision-making. Indigenous information systems are dynamic, and are continually influenced by internal creativity and experimentation as well as by contact with external systems. (Flavier et al., 1995 cited in Boven \& Morohashi, 2002, p. 12)

It is perhaps the distinct cultural context of IK in that

“indigenous peoples' communities, despite the pressure to integrate within the larger society of the national states of which they are part, still have their own distinct cultures' that distinguishes it from LK as 'local communities, usually do not have a cultural identity that sets them apart from the large society, or at least not to the same extent as in the case of indigenous peoples' communities". (Viergever, 1999, p. 333)

Sami scholars Porsanger and Guttorm (2011, cited in Helander-Renvall \& Markkula, 2017) use the concept árbediehtu (inherited knowledge), and state that árbediehtu is 'the collective wisdom and skills of the Sami people used to enhance their livelihood for centuries. It has been passed down from generation to generation both orally and through work and practical experience. Through this continuity, the concept of árbediehtu ties the past, present and future together' (pp. 105-106).

In drawing from these compendia it is apparent as we progress through the individual chapters that whatever definition is used, sharing knowledge is key to sustainable resource management. Allied to this is the realization that such knowledge 'encompasses dynamic and complex bodies of know-how, practices and skills' and has relevance not only for sustainability but resilience 'as it tends to be holistic, dynamic and adaptive in character' (Sumane et al., 2018, p. 233). The fact that local knowledge takes into account social, environmental, economic and spiritual aspects means 'it is at the core of practices that tend to respect, optimally-use and regenerate local, natural and social resources to meet human needs and ensure their livelihoods in the long term' (Sumane et al., 2018, p. 233).

\section{BUILDING SHARED KNOWLEDGE CAPITAL}

The contributors to this book have been involved in numerous academic and practice-based projects that have addressed the collection, processing and dissemination of environmental information needed for decision-making in planning. One of the many views from these projects is that the technology to collect, combine and analyse data from our environment has been available for decades and that the amount of available data is growing constantly. Technologies such as remote sensing, GIS and the internet allow fast and spatially accurate information to be produced without physically visiting the 
locations that the information is for. In addition, present technologies allow for the collection of information at very broad scales covering virtually the whole globe. On the other hand, while there have been ILK (and its associated terms) based reports in existence for a number of decades (even back to the 1950s) they are much less widely available. The evolution of internet-based participatory mapping systems (Public Participation Geographic Information Systems (PPGIS), or depending on the connotation, Participatory GIS (PGIS)), also allows community-based and spatially explicit information, such as ILK, to be accrued in a faster and much more accessible way. It is equally important to note nonetheless, in the context of this book in particular, that while PPGIS has been widely used in the collection of located information from urban environments, there are notably fewer examples of PPGIS having been used in rural and sparsely populated areas.

Building Shared Knowledge capital to Support Natural Resource Governance in the Northern Periphery (hereafter referred to as the BuSK project), was developed to address this inattention and by consequence help promote knowledge sharing and participatory methods of decision-making in northern peripheral areas of Europe. The project was designed in 2014-2015 by scientists from universities and research institutes together with local municipality civil servants consisting of 11 main partners: Natural Resources Institute Finland (Lead partner), Metsähallitus (Finland), City of Rovaniemi (Finland), University of Lapland (Finland), National University of Ireland Galway (NUIG), Swedish University of Agricultural Sciences SLU, University of Faroe Islands, University of Iceland, The Arctic University of Norway, Greenland Institute of Natural Resources and Qeqqata Municipality (Greenland) and 32 associate partners. The application for funding was submitted in 2015 to the EU Northern Periphery and Arctic Programme (NPA), a part of the European Territorial Cooperation Objective (Interreg) supported by the European Regional Development Fund (ERDF) with equivalent funding from non-EU countries. The aims of the NPA are 'to help to generate vibrant, competitive and sustainable communities, by harnessing innovation, expanding the capacity for entrepreneurship and seizing the unique growth initiatives and opportunities of the Northern and Arctic regions in a resource efficient way' (NPA, n.d.). The programme area itself shares a number of common features, such as low population density, poor accessibility, minimal economic diversity, abundant natural resources, and high impacts from climate change.

BuSK was funded from the NPA Priority Axis Four - Protecting, Promoting and Developing Cultural and Natural Heritage - with a timeframe from 1 June 2016 to 31 August 2019. The objectives of BuSK were to advance the collection of local knowledge in land use planning and to promote ways in which science-based knowledge and local / traditional / indigenous / experience-based knowledge could be combined in decision-making pro- 
cesses. BuSK was organized into four work packages: WP1 explored indigenous and local knowledge as part of cultural heritage and was designed to develop and provide tools, methods and practices for integrating indigenous and local knowledge (ILK) into land use planning and decision-making. WP2 dealt with collaborative planning and management of the commons and protected areas. Here the focus was on the relationships between state agencies and local communities and how the difficulties of collaboration in land use management decision-making were operationalized. WP3 concentrated on building knowledge for creating and developing sustainable community economies. This work package explored, from the point of view of communities and SMEs, the combining of local with expert knowledge for sustainable land use in peripheral areas. The final work package, WP4 explored issues of self-governance and the co-production of knowledge as targeted at the Social Licence to Operate (SLO) of large-scale projects in industry and other livelihoods such as tourism and forestry.

Specific studies were carried out across all partner countries, with evidence gathered from tourist entrepreneurs' views and solutions to tourism crowding in Iceland and Finland; PPGIS data from the island of Sandoy in the Faroe Islands and from the tourist Santa Claus Village in Rovaniemi; interviews carried out and discussions had with local people and farmers on land use practices, perceptions and values in Greenland and Ireland; PPGIS data being gathered and collated in the transboundary areas of Finland, Sweden and Norway with documentary analysis and PPGIS carried out for mapping a Social Licence to Operate (SLO) in mining, tourism and forestry.

\section{THE STRUCTURE OF THE BOOK}

The remainder of this book is structured into ten topic-related chapters with a concluding chapter that presents an overall view of the main findings. While there are different stories being told there are clear commonalities in all chapters. Through the various lenses employed, both in topic and location, the chapters make clear the usefulness in combining all-too-often separated knowledge systems to co-design and co-produce methods and solutions with an overwhelming case made for the sharing of knowledge horizontally rather than hierarchically.

In the next chapter (Chapter 2) a comparative analysis on the use of traditional and local knowledge in land use planning is probed by Turunen et al. Based on case studies and interviews with land use planning authorities and local residents in Finland, Sweden and Greenland, the authors examine how indigenous and local knowledge (ILK) has been taken into account in land use planning, the challenges encountered and best practice options to be considered. The chapter examines the legitimacy of local knowledge in the 
cases studied and considers how this is often mediated in different ways as well as exploring the implications this has on natural resource governance. The authors apply a Multiple Evidence Base approach (MEB) to the data in order to achieve more transparent ways of connecting different knowledge systems in planning processes and land use policy based on equity and reciprocity (Tengö et al., 2014). With this, the authors determine that the main challenges from the three case studies are at the core of indigenous peoples' rights and self-determination: recognition of their unique knowledge, legal protection of their culture and way of life, and co-management of resources (see also Goetze, 2005; Christensen \& Granti, 2007). They conclude that developing a PGIS method in combination with the knowledge co-production mode and the application of international guidelines such as the Akwé: Kon procedure, can play an important role in enhancing indigenous peoples' opportunities to participate, and promote recognition of their rights.

Chapter 3, by Tuulentie et al., probes further what people need and want, by connecting to the question of knowledge and how it is 'owned' by indigenous or other communities. What becomes evident here is that this knowledge has a wide scope and can range from the political power of maps to the guarded nature of community-owned knowledge. Consequently, the ability to understand and deconstruct the willingness to share such knowledge is an important aspect in overall issues of decision-making and governance. The chapter endeavours to unpack the complexities involved in this arena by drawing on the indigenous milieus as played out in the case studies of Finland, Sweden and Greenland. The description of the different cases shows how indigenous and local knowledge can be collected and used in different ways and also, how different societal situations affect that collection. Some conclusions suggest that questions remain around issues such as the internal heterogeneity of communities, the right to express individual views of traditional knowledge, and also the role of local people other than indigenous peoples in areas where they live adjacent to one another.

Interwoven within all these chapters is the topic which is explored in Chapter 4, namely that of gender perspectives on indigenous and local knowledge (ILK) to support natural resource governance. In this chapter, Lidestav et al. weave their narrative through a theoretical and analytical framework that combines indigenous and local knowledge as part of cultural heritage. In particular, the authors draw from three gender perspective frameworks, namely: Gender as an empirical variable and/or; Gender as a relational and structuralizing category and/or; Gender as a meaning category. The chapter not only explores how gender plays out through ILK in the case studies, but also considers what the implications of this are in relation to natural resource governance, planning systems, and how participatory GIS can contribute to include female gendered perspectives on the use of natural resources. 
Chapter 5, authored by Sandström et al., delves into the type of participation that we find in Participatory GIS (PGIS) and Public Participation GIS (PPGIS). The main idea here is one of exploring how spatial knowledge can enhance collaboration in planning. In particular, the chapter explores what is meant by public knowledge and who indeed the 'public' are. The chapter probes the appropriate levels of participation that should be sought and how this impacts not only the quality of the collected spatial data but also its likely successful incorporation into the planning process. The authors also consider the definitions and debates around PGIS and PPGIS while arguing that although these terms are not unambiguous, having a better understanding of what they are, and how these methods relate to expected outcomes and outputs, is an important part of the planning process. The authors conclude by demonstrating how the outcomes of the examples they chose emphasize the need to understand the 'public' in question, the many levels of participation that exist and the effect of different Participatory Mapping (PM) methods on data gathered.

The insights from Chapter 5 are very adeptly built on in Chapter 6 where examples from Finland, Sweden, Norway and the Faroe Islands, are explored by Nikula et al. in an effort to determine how PPGIS can be utilized for better understanding people's needs and wants. In this chapter it is quickly recognized that long-term commitment of institutions and stakeholders is required to build a process where different ways of producing and using knowledge in decision-making are utilized (see also Armitage et al., 2011). In particular, the commitment of administrative and political institutions to a participatory process is of key importance. At the core of this chapter is an unpacking of the usability and development needs of PPGIS on the basis of two studies of participatory mapping queries that address different types of land use issues. The first deals with the building and implementation of transboundary PPGIS in the three Nordic countries, Finland, Sweden and Norway. Here, despite informal borders and continuous interaction between citizens, cultural differences exist between local inhabitants and visitors that are reflected in people's views of different land use modes. The second uses PPGIS in the context of land use planning to grow tourism in the Faroe Islands where tourism infrastructure often conflicts with local land ownership and traditional land use. The authors conclude that in cases like these the co-production of knowledge and co-management of land and natural resources call for special attention to traditional and cultural ways of perceiving and understanding the environment (see also Sieber, 2006). They also highlight how a critical issue may be the representation of knowledge, that is, how intangible values can be converted and presented in the PPGIS environment. Overall, the authors conclude that there remains the need for a better human-computer interface which recognizes the requirements of various respondent groups' cultural backgrounds, the ability to use computers and the processes that are involved in planning. 
In Chapter 7, the theme pursued by Ólafsdóttir et al. relates to the contradictory role of tourism in the northern peripheries. At the core of this chapter is the long-heralded truism that demands both the expansion and development of tourism for employment and economic survival and the need to curtail tourism to ensure social and environmental sustainability and contradictorily to safeguard the tourism product itself. As tourism expands at a runaway pace across the region, the authors suggest that in many ways, smaller Arctic communities often do not benefit from this expansion and conversely suffer environmental impacts and disruption to everyday life and traditional activities. Such a consequence reinforces the predicament that this chapter endeavours to engage with. Drawing on experiences from Finland, Iceland, the Faroe Islands and Greenland, the chapter concludes with some insights into how policy makers and practitioners engage with the concepts of overtourism and sustainable tourism and on how local knowledge and public participation in rural tourism management processes can support local wellbeing. The authors in particular argue that tourism has to be responsible. Their concluding contention is that quality tourism is more likely to promote better places to live and better places to visit, rather than quantity tourism; a situation befitting the northern peripheries with their vulnerable natural and cultural environments.

Local sustainability perceptions and understandings are also at the core of Chapter 8 by McDonagh et al. The fundamental challenge here is the need to strike some sort of workable balance between economy, society and environment while realizing that conflicting views and different priorities will inevitably challenge the striking of such a balance. The political and institutional environment undoubtedly plays a role here as both driver and barrier to sustainability. It is subsequently argued that knowledge and understandings of different actors are shaped by the relationships forged by landscape, culture, social and economic contexts. People have to respond and adjust to policies on sustainability in their daily lives, and it is therefore necessary to explore how this is understood at the local level and subsequently impacts decision-making processes. This chapter draws from research conducted in Ireland and Iceland and explores how it is necessary now more than ever to take into account the micro-level, context-specific concerns of stakeholders. Questions that emerge throughout the chapter centre on: how local factors shape understandings of sustainability; how different understandings impact both participation in and response to sustainability decision-making; how sustainability is understood and engaged with when it presents quite different patterns of behaviour and expectation. In fact, what emerges here is that the values people attach to place, be they traditional or even emotional, make understanding sustainability a complex and multi-layered concept.

The message from Chapter 8 continues in Chapter 9 where McDonagh et al. look to Ireland and Iceland to understand other intricacies and the 
usefulness once again of 'listening to the locals'. In this chapter the focus is on local knowledge, what it is, from whom it derives and its place in the decision-making process. The central argument is that mechanisms to engage local people and extract local knowledge are key to rediscovering and revitalizing different local and non-local resources (see also van der Ploeg et al., 2000; van der Ploeg \& Renting, 2000). It becomes evident from the case studies that while different actors disseminate knowledge, this knowledge has to be translated and adjusted to local conditions that are often better understood by local people. Indeed, this is expertly uncovered in the Irish example where local knowledge was a catalyst for change in terms of the type of farming practices adopted. The authors also bring to the fore the ways in which the State can draw on the knowledge of local communities for the overall betterment of both State and community particularly in terms of delivery on the ground. Alongside the compelling argument for capacity building, necessary resources and training, what emerges is the need to follow targeted policy interventions and management practices derived in conjunction with local stakeholders and appropriate to the landscape in which they are rolled out. It is only in doing this that local buy-in can be garnered. Ultimately if knowledge sharing practices are to be fostered, scientific knowledge cannot be ignored, but systemic change away from conventional modes of thinking about knowledge transfer and participation is required.

Chapter 10 provides perhaps one of the richest illustrations of how theory and practice combine to great effect in forcing change both in thinking and policy. In this chapter, Sandström et al. bring us on a journey through reindeer grazing lands and movement routes, major road and rail infrastructure, large government organizations (The Swedish Transport Authority (STA)) mapping, PGIS and drone technology. Here, the authors demonstrate how, in trying to find workable solutions to help support traditional practices of reindeer herding, one can learn from indigenous and local knowledge (ILK) and utilize technology (PGIS) and planning practices to support and adapt to local needs and wants. Sandström et al. weave a very interesting narrative from their initial goal under the BuSK project of mapping and documenting, to one where the authors describe themselves as being fundamental in bringing case-specific indigenous and local knowledge (ILK) into a new and ongoing planning process, in order to challenge existing and future problems. The chapter explains, through the narrative of those involved (particularly the Gran reindeer herders themselves) how combining techno-scientific information, supported by historical research and knowledge, contributed to improved dialogue (with the Swedish Transport Authority (STA)) leading to innovative solutions towards better connected landscapes. The authors also point to how experience and development of tools for mapping, mutual learning processes and knowledge communication are crucial to the implementation of a collab- 
orative participation approach. Merging of knowledge systems was central to the research objectives with the authors suggesting that their contribution was to support and strengthen the ILK holders' knowledge production and to provide tools and strategies for them to deliver their new knowledge into the parallel planning process with the STA. That there was a very substantial and visible outcome in the construction of the first ever reindeer overpass over the E4 made for a huge step forward in understanding reindeer husbandry needs, and speaks volumes for the importance of bridging these knowledge systems.

Chapter 11 continues with the theme of public participation and giving voice to local people. Here, Suopajärvi et al. probe the complex arena that is social licence to operate (SLO) and how this presents challenges for industry and local communities in Norway and Finland. Social licence to operate essentially means local acceptance of industrial developments whereby the location of such industry is not only accepted, but is one which benefits host-communities. In this chapter, the authors probe how different industries, such as mining, tourism, forestry and fish-farming, strive to achieve local acceptance for their businesses in Northern Finland and Northern Norway. As these regions are not only rich in natural resources but also have competing interests related to land use, there are many contested values and interests related to these different livelihoods. Consequently we are also warned that if SLO is portrayed as listening to all stakeholders, including financiers and customers for example, then the emphasis put on the local community can be very much diluted. Among the many questions posed in the chapter are those which demand consideration of the legitimacy a company has to intervene with nature that conditions people's lives. This is particularly relevant in areas where livelihoods that use natural resources operate in a set environment, and therefore present a strong argument for respecting local residents' views. In all, the authors suggest that while the SLO focus has been on a small number of companies in the Nordic countries, the issues raised have global relevance and can be easily recognized when probing the legitimacy of the power that many global companies now possess. The position of large commercial companies, and their alliances with governments, impact our daily lives and as this chapter illustrates, local battles tend to end up with winners and losers. Consequently, the deliberations around social acceptance and the importance of SLO, particularly as it relates to big industries still has a long way to go.

The final Chapter 12 sees McDonagh and Tuulentie draw together the main issues debated throughout the book. In particular the attention here is on the challenges and concerns that permeate local communities and the (dis)connect between decision-making practices and those on who such decisions impact. The chapter brings together the various connotations that emerge from the different debates played out in the chapters and their probing of issues such as land resource use and management, local and indigenous knowledge and the 
broader aspect of governance and national policies as they impact on northern peripheral regions. This chapter also links back to the initial discussion on the way that ILK is conceptualized in relation to scientific and expert knowledge, and proposes a more constructive application of its core tenets in terms to future natural resource governance debates and strategies.

\section{REFERENCES}

Armitage, D., Berkes, F., Dale, A., Kocho-Schellenberg, E. \& Patton, E. (2011) Co-management and the co-production of knowledge: Learning to adapt in Canada's Arctic. Global Environmental Change, 21, pp. 995-1004.

Berkes, F. (1993) Traditional ecological knowledge in practice. In: Inglis, J. (ed.) Traditional Ecological Knowledge; Concepts and Cases. Ottawa: Canadian Museum of Nature and the International Development Research Centre, pp. 1-9.

Boven, K. \& Morohashi, J. (2002) Best Practices using Indigenous Knowledge. Nuffic, The Hague, the Netherlands, and UNESCO/MOST, Paris.

Casimirri, G. (2003) Problems with integrating traditional ecological knowledge into contemporary resource management. XII World Forestry Congress, Quebec City, Canada 2003.

CBD (1992) Convention on Biological Diversity (CBD). https://www.cbd.int/ traditional/intro.shtml (accessed 11 November 2019).

CBD (2018) Integration of Article 8(j) and provisions related to indigenous peoples and local communities in the work of the Convention and its Protocols. https://www .cbd.int/doc/decisions/cop-14/cop-14-dec-17-en.pdf (accessed 10 December 2019).

Christensen, J. \& Granti, M. (2007) How political change paved the way for indigenous knowledge: The Mackenzie Valley Resource Management Act. Arctic, 60, pp. 115-123.

FAO (n.d.) What is local knowledge. http://www.fao.org/docrep/007/y5610e/y5610e01 .htm (accessed 10 December 2019).

Goetze, T.C. (2005) Empowered co-management: Towards power-sharing and Indigenous rights in Clayoquot Sound, BC. Anthropologica, 47, pp. 247-265.

Helander-Renvall, E. \& Markkula, I. (2017) On transfer of Sami traditional knowledge: Scientification, traditionalization, secrecy and equality. In: Valkonen, X. (ed.) Indigenous Peoples' Cultural Heritage: Rights, Debates and Challenges. Koninklijke: Brill, pp. 104-129.

Kuokkanen, R. (2000) Towards an 'Indigenous paradigm' from a Sami perspective. The Canadian Journal of Native Studies, 20 (2), pp. 411-436.

McGregor, D. (2004) Traditional ecological knowledge and sustainable development: Towards coexistence. In: Blaser, M., Feit, H.A. \& McRae, G. (eds) In the Way of Development. London: Zed Books, pp. 72-91.

Nakashima, D. (2010) Indigenous Knowledge in Global Politics and Practice for Education, Science and Culture. UNESCO: Paris.

NPA (n.d.) Northern Periphery and Arctic Programme 2014-2020. www.interreg-npa .eu (accessed 10 December 2019).

Porsanger, J. \& Guttorm, G. (2011) Building up the field study and research on Sami traditional knowledge (Árbediehtu). In: Porsanger, J. \& Guttorm, G. (eds) Working with Traditional Knowledge: Communities, Institutions, Information Systems, Law and Ethics. Copenhagen: Norden (Diedut), pp. 13-57. 
Sieber, R. (2006) Public participation geographic information systems: A literature review and framework. Annals of the Association of American Geographers, 96 (3), pp. 491-507. https://doi.org/10.1111/j.1467-8306.2006.00702.x.

Sumane, S., Knickel, K., Strauss, A., Kunda, A., Rios, I. De Los, Rivera, M., Calcao Chebach, T., Ashkeazy, A. \& Tisenkopfs, T. (2018) Local and farmers knowledge matter! How integrating informal and formal knowledge enhances sustainable and resilient agriculture. Journal of Rural Studies, 59, pp. 232-241.

Tengö, M., Malmer, M., Brondizio, E., Elmqvist, T. \& Spierenburg, M. (2014) Connecting diverse knowledge systems for enhanced ecosystem governance: The multiple evidence base approach. Ambio, 43, pp. 579-591.

Tovey, H. (2009) Managing rural nature: Regulation, translations and governance in the Republic of Ireland and Northern Ireland. In: McDonagh, J., Varley, T. \& Shortall, S. (eds) A Living Countryside? The Politics of Sustainable Development in Rural Ireland. London: Ashgate, pp. 107-122.

UNESCO (n.d.) Local and Indigenous knowledge systems. http://www.unesco.org/ new/en/natural-sciences/priority-areas/links/related-information/what-is-local-and -indigenous-knowledge/ (accessed 10 November 2019).

van der Ploeg, J.D. \& Renting, H. (2000) Impact and potential: A comparative review of European rural development practices. Sociologia Ruralis, 40 (4), pp. 529-543.

van der Ploeg, J.D., Renting, H., Brunori, G., Knicknel, K., Mannion, J., Marsden, T., DeRoest, K., Sevilla-Guzman, E. \& Ventura, F. (2000) Rural development: From practices and policies towards theory. Sociologia Ruralis, 40 (4), pp. 391-408.

Viergever, M. (1999) Indigenous knowledge: An interpretation of views from Indigenous Peoples. In: Semali, L.M. \& Kincheloe, J.L. (eds) What is Indigenous Knowledge? Voices from the Academy. New York: Garland Publications, pp. 333-359. 